\title{
REDUÇÃO DA MAIORIDADE PENAL NO BRASIL: INCOMPATIBILIDADE JURÍDICA E SOCIAL DE SUA APLICAÇÃO
}

\section{REDUCTION OF CRIMINAL MAJORITY IN BRAZIL: LEGAL AND SOCIAL INCOMPATIBILITY OF ITS APPLICATION}

Suzana Cysneiros Sampaio

Ana Laura Piase

A verdadeira reeducação deveria começar pela sociedade, antes que pelo condenado: antes de querer modificar os excluidos, é preciso modificar a sociedade excludente, atingindo assim, a raiz do mecanismo de exclusão. (BARATTA, 2011, p. 186)

RESUMO: Trabalho destinado ao estudo da temática da redução da maioridade penal no Brasil, o qual se justifica por tratar de questões sociojurídicas que afetam o problema social da criminalidade infantojuvenil. Portanto, essa abordagem é relevante porque pode ampliar o conhecimento atual e fomentar o debate acerca da redução da maioridade penal. Destarte, pôde-se constatar que as propostas reducionistas, difundidas pelo sentimento de vingança social, além de não serem adequadas para solucionar a questão em toda a sua extensão, são incabíveis do ponto de vista jurídico e incapazes de resolver os inúmeros problemas sociais que consubstanciam a prática de infrações por adolescentes.

Palavras-chave: Criminalidade infantojuvenil; Inimputabilidade penal; Adolescente em conflito com a lei.

\begin{abstract}
Work aimed at the study of the reduction of the age of criminal responsibility in Brazil, which is justified by addressing socio-legal issues that affect the social problem of juvenile crime. Therefore, this approach is relevant because it can expand current knowledge and encourage debate about reducing the age of criminal responsibility. Thus, it was possible to verify that the reductionist proposals, spread by the feeling of social revenge, in addition to not being adequate to resolve the issue to its full extent, they are legally incapable and unable to solve the countless social problems that substantiate the practice of infractions by adolescents.
\end{abstract}

Keywords: Juvenile criminality; Penal inimputability; Teenager in conflict with the law.

\section{INTRODUÇÃO}

A Constituição Federal de 1988 reconheceu as crianças e adolescentes como sujeitos de direito incluindo em seu corpo o princípio da Teoria da Proteção Integral. Nesse diapasão, o art. 228 do referido diploma legal estabeleceu a exceção da inimputabilidade penal aos indivíduos com menos de dezoito anos, tendo em vista a presunção legal de que eles apresentam uma imaturidade natural, considerando-se o critério 
biológico. Entretanto, atualmente, a sociedade tem fomentado debates relacionados ao tema da redução maioridade penal, especialmente por conta do aumento da criminalidade infantojuvenil.

Diante desse cenário, o presente artigo acadêmico tem por escopo abordar e ponderar a respeito da temática da redução da maioridade penal no Brasil, trazendo algumas reflexões acerca de sua inviabilidade no cenário jurídico e social brasileiro. Sendo assim, a problemática identificada emana do seguinte questionamento: Por que a redução da maioridade penal não é uma solução adequada ao problema social da criminalidade infantojuvenil considerando a implementação da Teoria da Proteção Integral pelo ordenamento jurídico brasileiro?

Isto posto, a investigação do tema que constitui o objeto de estudo justifica-se, em âmbito teórico, na medida em que aborda uma questão que não se esgota facilmente e, utilizando como parâmetro o marco da Teoria da Proteção Integral pelo ordenamento jurídico brasileiro torna possível a identificação das inúmeras adversidades que favorecem o problema social da criminalidade infantojuvenil, o que sustenta a proposição de que a mera redução da maioridade penal apresenta-se como solução inócua, pautada em percepções imediatas de uma realidade muito mais complexa. Portanto, essa abordagem pode ampliar o conhecimento atual acerca dessa questão, tendo em vista sua importância social.

Nesse sentido, a presente pesquisa tem como objetivo geral demonstrar que a redução da maioridade penal não se caracteriza como uma solução plausível para o problema da criminalidade precoce no Brasil, considerando aspectos sociojurídicos que circundam esse fenômeno. Em contrapartida, o estudo tem como objetivos específicos conhecer e identificar os principais fatores e conceitos que incidem sobre essa temática; analisar os problemas sociais que favorecem a entrada do adolescente para o mundo do crime; contrapor o senso comum de quem defende que a redução da maioridade penal é uma solução para a "impunidade" dos jovens infratores e; refletir sobre a necessidade de se buscar soluções que sejam adequadas ao problema social ora discutido.

A temática abordada será desenvolvida ao longo de três pontos principais. Inicialmente, no primeiro tópico, será apresentado um referencial teórico com noções e conceitos gerais pertinentes ao tema da maioridade penal. Dando continuidade, o segundo ponto fará uma discussão a partir dos argumentos contra e a favor da redução da maioridade penal no Brasil, discorrendo sobre questões jurídicas e sociais que, no contexto atual, impossibilitam a aplicação das propostas reducionistas. Enfim, o terceiro tópico será destinado à quebra dos mitos sociais, ou seja, a desmistificação de expressões difundidas pela sociedade provenientes do mero senso comum, as quais são utilizadas para defender a redução da maioridade penal no país, embora não sejam correspondentes com a realidade concreta que se estabelece diante do fenômeno da criminalidade infanto-juvenil.

Para tanto, a metodologia utilizada será pautada em uma pesquisa de caráter básico, fundada no método de abordagem dedutivo em conjunto com a análise qualitativa. Ademais, far-se-á o emprego das técnicas de pesquisa bibliográfica e documental. 


\section{NOÇÕES GERAIS SOBRE AMAIORIDADE PENAL}

Para a compreensão da temática da redução da maioridade penal no Brasil, faz-se pertinente a compreensão de conceitos provenientes da doutrina penal. Nessa conjuntura, a conduta, como elemento do fato típico, deu origem a diversas teorias a respeito da ação com repercussão na esfera penal. Em vista disso, as principais teorias que disciplinaram a temática da conduta foram a teoria naturalista, a teoria social da ação e a teoria finalista da ação.

A teoria naturalista tem fundamento na conduta como agente autêntico de causalidade, sem a formulação do juízo da ilicitude e da reprovabilidade da conduta. Já a teoria social da ação pauta-se no pressuposto de que a conduta deve ser considerada com base em padrões sociais, divergindo da teoria naturalista por não acolher as leis da natureza na sua estrutura constitutiva.

Por fim, a teoria finalista da ação baseia-se na ideia de que a conduta de um indivíduo observa o exercício de uma atividade finalista e não somente causal, ou seja, para a ação ser considerada delituosa ou não dependerá da análise de sua finalidade, a fim de identificar o direcionamento inicial do agente e sua consciência acerca dos efeitos causais de sua conduta.

Conforme ensina Damásio de Jesus (2013, p. 273), o criador e difusor dessa teoria foi o filósofo do direito alemão, Hans Welzel, o qual possibilitou por meio de seus estudos que a valoração da conduta produzisse efeitos na estrutura do tipo, da ilicitude e da culpabilidade. Destarte, a teoria finalista da ação vem sendo acolhida pela doutrina brasileira de forma majoritária.

Diante disso, com fundamento no finalismo de Welzel, toda conduta, ação ou omissão, típica e antijurídica será configurada como crime, localizando o dolo e a culpa como elementos do tipo e não da culpabilidade, como tradicionalmente era enunciado pela doutrina. Quanto à culpabilidade, ela se torna um pressuposto da aplicação da pena, incidindo sua aplicabilidade não sobre o fato, mas sobre o sujeito que pratica determinada conduta. Sendo elementos constitutivos dela, a imputabilidade, a potencial consciência da antijuridicidade e a exigibilidade de conduta diversa

Seguindo no progresso da discussão da redução da maioridade penal, é cabível o exame acerca do entendimento dos conceitos de ato infracional e de crime. Desta maneira, consoante Sousa, Oliveira e Campos (2014, p. 215-216), o ato infracional é operado diferentemente do crime comum, haja vista que a imputabilidade, um dos elementos do juízo de reprovabilidade, não estará presente quando se tratar de uma ação típica cometida por um indivíduo menor de 18 anos, estando essa definição de acordo com os arts. 103 e 104 da Lei federal n. 8.069 de 13 de julho de 1990, nomeada de Estatuto da Criança e do Adolescente - ECA, os quais determinam que:

Art. 103. Considera-se ato infracional a conduta descrita como crime ou contravenção penal.

Art. 104. São penalmente inimputáveis os menores de dezoito anos, sujeitos às medidas previstas nesta Lei. 
Nessa conjuntura, é possível perceber que o ECA segue os mesmos padrões de conceituação presentes em documentos internacionais de proteção à criança e ao adolescente. Como exemplo, pode-se ressaltar que esses conceitos foram preconizados pela Convenção sobre os Direitos da Criança, criada em 20 de dezembro de 1989, pela resolução 44/25, aprovada pela Assembleia Geral das Nações Unidas. Sendo assim, constata-se que o referido documento exerceu influência sobre o processo de estruturação e elaboração do ECA.

Nesse contexto, a Convenção sobre os Direitos da Criança foi ratificada pelo Congresso Nacional e promulgada pelo Decreto n. 99.710, em 21 de novembro de 1990, tornando-se parte integrante do corpo normativo brasileiro. Dentre os seus postulados, destaca-se que: "para efeitos da presente convenção considera-se como criança todo ser humano com menos de dezoito anos de idade, a não ser que, em conformidade com a lei aplicável à criança, a maioridade seja alcançada antes” (BRASIL, 1990).

No que diz respeito à amplitude da Convenção, esclarece Pereira (1992, apud. LIBERATI, 2012. p. 33) que:

Os direitos da criança reconhecidos na Convenção significam e representam o mínimo que toda sociedade deve garantir às suas crianças, reconhecendo, em um único código, todas as normas e medidas de privilégio e de proteção em favor das crianças, que, os Países Signatários, devem adotar e incorporar a suas leis.

De comum acordo está o documento internacional intitulado de Regras das Nações Unidas para a Proteção dos Menores Privados de Liberdade, instaurado em 14 de dezembro de 1990, na 68 Sessão Plenária da Assembleia Geral das Nações Unidas, o qual incorpora a interpretação de que jovem "é qualquer pessoa menor de 18 anos. A idade limite abaixo da qual não deve ser permitido privar uma criança de liberdade deve ser fixada por lei” (ASSEMBLEIA GERAL DAS NAÇÕES UNIDAS, 1990).

Ademais, no que tange ao desenvolvimento da questão da redução da maioridade penal na legislação brasileira, é indiscutível que essa matéria foi alvo de significativas modificações no percurso que vai do período Imperial até o contexto hodierno. Assim, é possível afirmar que no Período Imperial os indivíduos de 7 a 14 anos, gozavam de inimputabilidade penal relativa. Porém, no Período Republicano, com a vigência do Código Penal de 1890, a inimputabilidade penal relativa foi estabelecida entre 9 e 14 anos, entretanto, nesse mesmo período, a imputabilidade penal havia sido fixada a partir de 9 anos. Contudo, esse panorama foi modificado com a Lei Orçamentária, Lei n. 4.242 de janeiro de 1921, que trouxe novo entendimento sobre o assunto, dispondo que os menores de 14 anos estariam caracterizados como sujeitos inimputáveis, submetendo os jovens de 14 a 18 a um procedimento diferenciado do que era aplicado aos adultos. Corroborando com esse entendimento, foi instituído o primeiro Código de Menores do Brasil, o Decreto 17.943-A, de 1927.

Contraditoriamente, a maioridade penal de 18 anos foi estabelecida no período compreendido, historicamente, como o Estado Novo de Getúlio Vargas, revelando a escolha pelo critério biológico de aferição da responsabilidade penal. "Trata-se de uma presunção absoluta de inimputabilidade que faz com 
o menor seja considerado como tendo desenvolvimento mental incompleto em decorrência de um critério de política criminal" (SOUSA; OLIVEIRA; CAMPOS, 2014, p. 2016).

Atesta-se o acolhimento do critério biológico no tocante a maioridade penal pelo art. 26 do Código Penal de 1940, o qual enuncia que "os menores de 18 (dezoito) anos são penalmente inimputáveis, ficando sujeitos às normas estabelecidas na legislação especial” (BRASIL, 1940). Nesse segmento, a Constituição Federal de 1988 consolidou a inimputabilidade em seu art. 228, aduzindo que "são penalmente inimputáveis os menores de dezoito anos, sujeitos às normas da legislação especial” (BRASIL, 1988).

Isto posto, o jovem com menos de 18 anos, autor de uma infração, seja ela correspondente a uma contravenção penal ou a um crime, não permanecerá sob a égide do processo criminal comum, porque tal situação será regida por normas de caráter especial, passando essa matéria a ser disciplinada pelas medidas socioeducativas presentes no ECA, as quais estão previstas nos artigos 98 a 128, além da seção V, do art. 171 ao art. 190, da enunciada legislação.

Apesar do que dispõe a legislação, muito se tem discutido acerca da questão da redução da maioridade penal no Brasil atualmente, tendo na doutrina posicionamentos favoráveis e desfavoráveis aos projetos reducionistas. Portanto, com base no referencial teórico ante exposto, é importante minuciar a questão em face da realidade sociojurídica nacional.

\section{A CONTROVÉRSIA dA REDUÇão dA MAIORIDAdE PENAL DIANTE DA REALIDADE SOCIOJURÍDICADO BRASIL}

Diante do que foi exposto, com base nos documentos internacionais e dispositivos normativos presentes na legislação brasileira, é correto o julgamento de que o jovem deve ser visto sob a prerrogativa de ser uma pessoa em peculiar fase de desenvolvimento, de modo que cada etapa desse estágio - da primeira infância até a adolescência -, deve ser considerada de forma integral, levando-se em consideração todas as peculiaridades intrínsecas a esse período da vida. Nesse cenário, tal compreensão do menor de 18 anos é coerente com a positivação da criança e do adolescente como sujeitos de direitos, em outras palavras, como personagens ativos e pertencentes ao sistema jurídico, o que afasta a idealização de que eles são simples figuras manipuladas pelos adultos, situando-os, finalmente, como protagonistas dentro do contexto sociojurídico atual.

Para uma maior abrangência dessa discussão é imprescindível uma fundamentação pautada nos princípios que regem as Diretrizes das Nações Unidas Para a Prevenção da Delinquência Juvenil - Diretrizes de Riad, criada por meio da Resolução 45/112, do oitavo Congresso das Nações Unidas sobre prevenção do delito e do tratamento do delinquente, em 14 de dezembro 1990, a qual é composta pelos seguintes juízos principiológicos: 
desenvolver atitudes não criminais.

2. Para ter êxito, a prevenção da delinquência juvenil requer, por parte de toda a sociedade, esforços que garantam um desenvolvimento harmônico dos adolescentes e que respeitem e promovam a sua personalidade a partir da primeira infância.

3. $\mathrm{Na}$ aplicação das presentes Diretrizes, os programas preventivos devem estar centralizados no bem-estar dos jovens desde sua primeira infância, de acordo com os ordenamentos jurídicos nacionais.

4. É necessário que se reconheça a importância da aplicação de políticas e medidas progressistas de prevenção da delinquência que evitem criminalizar e penalizar a criança por uma conduta que não cause grandes prejuízos ao seu desenvolvimento e que nem prejudique os demais. Essas políticas e medidas deverão conter o seguinte:

a) criação de meios que permitam satisfazer às diversas necessidades dos jovens e que sirvam de marco de apoio para velar pelo desenvolvimento pessoal de todos os jovens, particularmente daqueles que estejam patentemente em perigo ou em situação de insegurança social e que necessitem um cuidado e uma proteção especiais;

b) critérios e métodos especializados para a prevenção da delinquência, baseados nas leis, nos processos, nas instituições, nas instalações e uma rede de prestação de serviços, cuja finalidade seja a de reduzir os motivos, a necessidade e as oportunidades de cometer infrações ou as condições que as propiciem;

c) uma intervenção oficial cuja principal finalidade seja a de velar pelo interesse geral do jovem e que se inspire na justiça e na equidade.

d) proteção do bem-estar, do desenvolvimento, dos direitos e dos interesses dos jovens;

e) reconhecimento do fato de que o comportamento dos jovens que não se ajustam aos valores e normas gerais da sociedade são, com frequência, parte do processo de amadurecimento e que tendem a desaparecer, espontaneamente, na maioria das pessoas, quando chegam à maturidade; $\mathrm{e}$,

f) consciência de que, segundo a opinião dominante dos especialistas, classificar um jovem de "extraviado", "delinquente" ou "pré-delinquente" geralmente favorece o desenvolvimento de pautas permanentes de comportamento indesejado.

5. Devem ser desenvolvidos serviços e programas com base na comunidade para a prevenção da delinquência juvenil. Só em último caso recorrer-se-á a organismos mais formais de controle social. (ASSEMBLEIA GERALDAS NAÇÕES UNIDAS, 1990)

Os princípios supracitados baseiam-se no pressuposto básico de que proporcionando ao jovem os meios necessários e primordiais para o seu desenvolvimento e socialização tornar-se-á possível atenuar e definir os índices de criminalidade, em concordância com um processo inverso de estigmatização do ser em fase de formação identitária. Sendo essa situação concretizada com a interferência do Poder Público, da sociedade e da família, faz-se reiteradamente evidente a importância da Teoria da Proteção Integral nesse contexto, tanto para prevenir o surgimento dos fatores que impelem a criança e o adolescente para o mundo do crime, quanto para remediar e lidar com as consequências do problema social da criminalidade infantojuvenil.

Pela Teoria da Proteção Integral entende-se um conjunto de mecanismos adotados por um Estado na direção de promover a efetivação de direitos das crianças e dos adolescentes, indo contra a seletividade protetiva e dirigindo-se a todos esses indivíduos, sem distinção de qualquer espécie. Desse modo, o art. 227 da Constituição Federal de 1988 consolidou o entendimento dessa teoria dentro do ordenamento jurídico brasileiro, aduzindo que:

É dever da família, da sociedade e do Estado assegurar à criança, ao adolescente e ao jovem, com absoluta prioridade, o direito à vida, à saúde, à alimentação, à educação, ao lazer, à profissionalização, à cultura, à dignidade, ao respeito, à liberdade e à convivência familiar e comunitária, além de colocá-los a salvo de toda forma de negligência, discriminação, exploração, violência, crueldade e opressão. (BRASIL, 1988) 
Em conformidade com esse dispositivo, entende-se que deve ser garantida à criança e ao adolescente a sua proteção integral no meio social, resguardando-os das intempéries e dos conflitos que possam, de alguma maneira, proporcionar consequências nefastas ao seu peculiar processo de desenvolvimento. Entretanto, verifica-se atualmente uma situação diametralmente oposta ao que preceitua a legislação, uma vez que, está situada no centro dos debates favoráveis à redução da maioridade penal, parcela considerável da sociedade brasileira que, por conseguinte, reflete imagens controvertidas no Estado.

Como afirma Liberati, (2012, p. 62) "aquilo que é identificado como vontade da Constituição deve ser honestamente preservado", e acrescenta que, "a preservação de um princípio constitucional fortalece o respeito à Constituição e assegura um bem jurídico indispensável à essência do Estado Democrático". Por isto, apesar das vertentes reducionistas, o debate acerca de tal temática percorre linhas mais tênues dentro do paradigma jurídico brasileiro, haja vista que em consonância com entendimento do Supremo Tribunal Federal - STF, por meio da ADI 939/DF, rel. Min. Sydney Sanches, em 15 de setembro de 1993, compreendese que os direitos fundamentais estão dispostos difusamente na Constituição Federal de 1988, ou seja, não se exaurem no rol apresentado pelo art. $5^{\circ}$ (BRASIL, 1993).

Então, firmado nessa premissa, Andrade (2013) elucida que o art. 228, da CF/88 figura como direitogarantia individual destinado às crianças e adolescentes, sendo insuscetível de mudança por projeto de emenda constitucional. Nessa perspectiva, reduzir a maioridade penal representaria a violação de um direito fundamental, de modo que, além de ser tese contrária aos preceitos sustentados pela Teoria da Proteção Integral, caracterizaria um grave retrocesso social.

Uma vez que a matéria é versada de forma muito mais vasta, é de importância capital o exame da forma pela qual o debate da redução da maioridade penal manifesta-se no âmbito social do Brasil. Com o aumento do número de casos de delitos praticados por jovens, surge na sociedade brasileira um sentimento de temor que motiva uma aproximação do que se entende ser uma solução idônea para o problema. Inequivocamente, podemos identificar a criminalidade como um fator de instabilidade no âmbito comunitário e que, consequentemente, pressupõe uma reação social, apresentadas, em regra, como ações preventivas ou repressivas. Faz-se oportuno discorrer sobre as condutas e medidas repressivas, tendo como base o fato de que o Estado e a sociedade brasileira pautaram-se nessa perspectiva como meio viável de combate ao fenômeno controvertido da criminalidade precoce.

Isto posto, a punição revela o temor da incerteza no evento futuro, mas também expõe a moral, os valores e preceitos cultivados em determinada sociedade. É de evidente constatação que o ser humano sempre sentiu a necessidade de ser protegido contra as intempéries decorrentes ora de fatos naturais, ora humanos. A proteção, nesses termos, pressupõe o distanciamento da possibilidade de ocorrência da situação que o colocaria em risco. Historicamente, tendemos a deslocar os "desvios" sociais para ambientes distantes do convívio coletivo, entendendo distância não como espaço geográfico, mas como espaço estratificado e institucionalizado que, consequentemente, configura-se como uma barreira muito mais difícil de ser transposta. 
Por um processo diacrônico, é notório que a população brasileira está inserida em um ambiente em que a punição é supervalorizada, no qual os indivíduos não despendem esforços para criticar os sistemas de proteção ao jovem, tal como o ECA, afirmando que as medidas cabíveis aos jovens infratores engendram impunidade. Uma das noções básicas que delineiam a fundamentação do discurso de quem se posiciona favorável à redução da maioridade penal é a presunção de que há, no contexto hodierno, o desenvolvimento cognitivo adiantado do jovem, com base na rápida evolução da sociedade (BORRING, 2003, apud. CUNHA, ROPELATO, ALVES, 2006. p. 649).

Em consonância com a expectativa de grande parte da população, qual seja o encarceramento e punição "efetiva" dos jovens transgressores da lei, a ideia de Emenda à Constituição - PEC em prol da consolidação da redução maioridade penal já foi pauta de diversos projetos de lei que ensejaram tal mudança. Dentre esses, pode-se citar a PEC n. $171^{1}$ de 19 de agosto de 1993, cuja autoria foi do ex-deputado Benedito Domingos, a qual intentava a mudança do art. 228 da Constituição Federal de 1988, com o intuito de estabelecer a imputabilidade penal ao maior de 16 anos. Torna-se manifesto que tal proposta, assim como as demais, contemplam os menores de 18 anos como passíveis de imputação pela crença de que esses indivíduos já possuem o desenvolvimento apurado para determinar suas condutas e serem responsabilizados por essas, encontrando-se o art. 228 incompatível com a realidade atual do jovem moderno.

Outrossim, o sentimento punitivista difundido na sociedade brasileira se justifica tanto pelo aumento da criminalidade dentre a população infantojuvenil, como pela implantação da cultura do medo (PASTANA, 2003, apud. PASTANA, 2007, p. 208), na qual se percebe que as medidas sancionatórias de maior severidade são legitimadas na proporção em que se acredita que elas são meios plausíveis para amenizar a problemática social da criminalidade, configurando uma busca por segurança, mesmo sendo apenas uma figura representativa de uma realidade distante. $O$ grande problema reside quando o enrijecimento penal e a redução da maioridade penal são encarados como únicas alternativas remediadoras da criminalidade.

Ademais, no deslinde da temática da criminalidade, percebemos o quão sensível é o assunto quando se trata do reconhecimento de instituições que fomentam o comportamento "desviante". Embora não haja a assunção das causas intrínsecas da criminalidade pelo discurso da maioria, discorrer sobre esse tema sem desviar o aspecto do indivíduo para o Estado, família e sociedade no que tange à responsabilização, é deturpar a importância do debate que é necessário ao desenvolvimento de medidas, de fato, adequadas à resolução dessa problemática.

De acordo com dados do Levantamento Nacional de Informações Penitenciárias - Infopen, coletados pelo Departamento Penitenciário Brasileiro - DEPEN, "entre os anos de 2000 e 2017, a taxa de aprisionamento aumentou mais de 150\% em todo país. Em junho de 2017, o Brasil registrou 349,78 pessoas presas para cada 100 mil habitantes" (DEPEN, 2017, p. 12). Com isso, o Brasil passou a ter a terceira maior

1 Para consultar o inteiro teor da PEC n. 171/1993, a qual está aguardando apreciação pelo Senado Federal, acesse: $<$ https://www.camara.leg.br/proposicoesWeb/fichadetramitacao?idProposicao=14493>. 
população carcerária do mundo², ademais, o sistema penitenciário não se desenvolveu para ter capacidade de comportar esse número crescente de encarcerados ${ }^{3}$. Diante disso, é possível indagar: Por que ainda consideramos como uma alternativa viável para solucionar o problema da criminalidade o rigor da punição, diante do modelo carcerário falho conhecido pela sociedade brasileira?

A dificuldade em responder tal questionamento acentua-se quando consideramos a questão da criminalidade infantojuvenil e a ideia de redução da maioridade penal, onde há uma crença, irracional, de que retirar o jovem do meio social, no qual, diga-se, há certo nível de ingenuidade para as práticas criminosas, e o inserir em um ambiente estritamente produtor de criminalidade irá, de alguma maneira, o reabilitar para a convivência social.

Nesse sentido, é essencial asseverar que os símbolos representantes de setores da vida em comunidade do adolescente são construídos pela experiência no transcurso de seu desenvolvimento, tornando-se lógico que, quando há defasagem dos meios de integração e socialização dos indivíduos, eles continuarão com o estigma de tal descompasso. Destarte, os jovens podem demonstrar condutas antissociais, as quais se não receberem a devida atenção e suporte do Estado, da sociedade e da família, serão decisivos para a manutenção de um ciclo que gera o fenômeno da criminalidade. Dessa forma, "a socialização ocorre dentro de uma cultura, que, sendo um meio permanente e total, modela profundamente os sujeitos que dela participam"(FURTADO, 2014, p. 27).

Anote-se, porém, que tratar o direito penal como uma solução para todos os fenômenos negativos sociais tornou-se um exercício corriqueiro entre a população brasileira, a qual leva ao âmbito legislativo demandas punitivas que clamam por maior atuação do Estado, ou seja, uma "efetiva" punição dos jovens infratores, enveredando-se através de um caminho que corrompe o processo de decisões político-jurídicas com estereótipos e preconceitos, ocupando, não raramente, o lugar da tecnicidade da lei (MIRAGLIA, 2005, apud. MACHADO, SANTOS, 2018, p. 276).

Conforme explana Lins, Figueiredo Filho e Silva (2016, p. 120-121), em relação a discussão da punição dos jovens infratores é de fácil compreensão que os argumentos que circundam tal temática estão, essencialmente, arraigados no senso comum e acima de tudo, em um pressuposto de vingança social, como forma retributiva aos prejuízos causados. Não obstante, a alegação de que as medidas cabíveis aos jovens infratores engendram impunidade configura-se como um argumento inválido, tendo em vista que não é finalidade das medidas socioeducativas a punição, tal como se configura no imaginário social, mas a reeducação, a reinserção e ressocialização do adolescente em conflito com a lei.

Nesse sentido, contata-se que a pouca preocupação em construir um debate pautado em evidências científicas e fiel às análises das raízes do problema social da criminalidade dá-se, em parte, pela

2 Conforme os dados do Infopen, até o período correspondente ao primeiro semestre de 2017, o quantitativo da população carcerária do Brasil era 726.354 pessoas (DEPEN, 2017,p. 8).

${ }^{3}$ De acordo com o Infopen, o sistema penitenciário brasileiro tinha, em 2017, 1507 estabelecimento prisionais ativos por todo o país, sendo que havia déficit de vagas em todas as Unidades da Federação (DEPEN, 2017, p. 22). Ao todo, havia uma carência superior a 300 mil vagas, com reflexos mais graves para os indivíduos condenados ao regime fechado (DEPEN, 2017, p. 25). 
desconsideração da população marginalizada, social e economicamente, como sujeitos indispensáveis para a construção da identidade nacional, sendo assim, passíveis de terem seus direitos ignorados no âmbito penal. Essa conjuntura faz a punição ser vista como "um instrumento de encarceramento de uma população considerada tanto desviante e perigosa, como supérflua, no plano econômico" (WACQUANT, 2001, apud. PASTANA, 2007, p. 210). Dessa forma, nota-se que os defensores da redução da maioridade penal pouco se preocupam em fazer uma análise correta do modelo carcerário ou em pensar soluções benéficas e concretas a longo prazo

Seguindo nessa mesma linha, configura-se imperioso a análise da pertinência que a criminologia crítica apresenta no tocante à temática da redução da maioridade penal. Numa análise objetiva, a criminologia crítica traz para o centro do debate sobre a criminalidade um elemento essencial para uma discussão racional sobre a temática, qual seja o fator econômico, mais precisamente as raízes econômicas da distribuição da renda. Evidencia-se, também, que a criminologia crítica põe em evidência a face que é influenciada pelo capitalismo no que se refere aos processos de criminalização, pois em conformidade com o status social do indivíduo incidirá sobre ele diferentes meios de educação e responsabilização.

Nesse cenário, é possível afirmar que a construção da personalidade marginalizada se inicia, não raramente, no próprio ambiente escolar, o qual assume o papel de propulsor no tocante a manutenção de tal estigma no indivíduo (BARATTA, 2011, p. 172). Essa proposição traz a ideia de que juntamente com o sistema penal, como fomentador da marginalização, vem o ambiente escolar, o qual precipuamente deveria fornecer uma maior socialização para indivíduos historicamente marginalizados, todavia, acaba por promover o processo inverso.

“O sistema escolar, no conjunto que vai da instrução elementar até a média e superior, reflete a estrutura vertical da sociedade e contribui para criá-la e para conservá-la, através de mecanismos de seleção, discriminação e marginalização" (BARATTA, 2011, p. 172). Assim, pode-se perceber que possuímos um sistema que seleciona e estigmatiza indivíduos desde a base do processo de desenvolvimento social e, nesse ínterim, carregamos uma esperança leviana de que esses mesmos sujeitos não apresentem comportamentos digressivos em qualquer etapa de suas vidas.

Verifica-se também que o sistema escolar, em toda sua disposição, se apresenta como um órgão responsável pelo amoldamento da criança e do adolescente provenientes dos grupos marginalizados em favor da cultura que prevalece no imaginário social, porém sem fornecer os meios efetivos para essa adaptação, o que irá implicar sanções a depender da desproporcionalidade dos comportamentos de tais indivíduos com a ordem social vigente e aceita (BARATTA, 2011, p. 173).

Nesse diapasão, resta evidente que as técnicas de ensino institucionalizadas tendem a uma socialização do corpo do jovem, com a finalidade primordial de facilitar o exercício do poder sobre a população marginalizada, compreendendo o corpo dócil como aquele que "pode ser submetido, que pode ser utilizado, que pode ser transformado e aperfeiçoado" (FOUCAULT, 2004, p. 126). 
Assim, observa-se que o Estado oferece para a população segregada todo um aparato de acolhimento de sua criminalidade, configurando o sistema carcerário como um prolongamento do trabalho do sistema escolar. Destarte, deslocando tais proposições para a realidade hodierna brasileira e para o âmbito dos debates sobre a redução da maioridade penal, torna-se patente que não se pode falar em legitimidade do sistema carcerário e, consequentemente, em medidas reducionistas, quando a falha começa no início da estrutura estatal de suporte para o desenvolvimento infantojuvenil.

Tomando como base as estruturas e a organização socioeconômica brasileira, não é de difícil compreensão que há pela classe detentora de privilégio econômico uma expectativa de manutenção da disposição sistemática que a tem beneficiado, mas que, em contrapartida, oprime e desvirtua as classes que não possuem capacidade econômica suficiente para adquirir o poder decisório dentro da seara política.

Em vista disso, é notório que não investir contra o pensamento punitivista é ir ao encontro de um Estado que não proporciona os direitos básicos e a proteção mínima que a Teoria da Proteção Integral preconiza à criança e ao adolescente em situação de vulnerabilidade. Além disso, cria um paradigma social que transfere ao adolescente em conflito com a lei a responsabilidade total por suas ações, ainda que esses mesmos indivíduos se encontrem desamparados e excluídos socialmente, o que favorece a prática de atos infracionais. Portanto, não desmitificar as ideias reducionistas é, sobretudo, estar de acordo com um sistema que se configura como "um campo de concentração [...] punitivo em caráter cotidiano, cruel e perpétuo" (ANDRADE, 2012, apud. MACHADO, SANTOS, 2018, p. 279).

Logo, é imprescindível a necessidade do reconhecimento de que a falha estatal em promover uma educação inclusiva para os jovens pertencentes às classes sociais inferiores, sendo tal circunstância associada às divergências e dificuldades econômicas enfrentadas por eles, influencia demasiadamente o aumento da criminalidade infantojuvenil. Ademais, articular discursos em torno da questão da redução da maioridade penal sem assumir a intervenção de tais fatores é guiar o discurso para medidas equivocadas de combate a essa problemática.

\section{DESMISTIFICAÇÃO DAS IDEIAS QUE SUSTENTAM O REDUCIONISMOATUALMENTE}

O sentimento punitivista presente no imaginário brasileiro apresenta-se como uma contradição ao novo paradigma político democrático que tem se desenvolvido e aperfeiçoado desde o advento da Constituição Federal de 1988. Destarte, quando analisada a maneira como o debate acerca da criminalidade infantojuvenil se desenvolve, fica nítido que os defensores do reducionismo na idade de imputabilidade penal acabam por afastar os ideais democratas dentro do âmbito de atuação da Justiça Penal brasileira, defendendo a figura do Estado punitivo ${ }^{4}$ como um meio adequado à resolução da violência urbana, baseado na ilusão de que

\footnotetext{
${ }^{4}$ A figura do Estado punitivo "caracteriza-se por diminuir suas prerrogativas na frente econômica e social e por aumentar suas missões em matéria de segurança, subitamente relegada à mera dimensão criminal” (WACQUANT (2001, apud. PASTANA, 2009, p. 122).
} 
"somente com a elaboração de leis severas é que o controle da criminalidade dar-se-ia de forma eficaz" (PASTANA, 2009, p. 124), inclusive quando se trata da questão dos adolescentes em conflito com a lei.

Sem embargo, a consolidação do Estado punitivo no Brasil traz contornos muito mais preocupantes, ao invés da solução dos problemas sociais contemporâneos, como no caso da delinquência infantojuvenil. Isso decorre em virtude de que, hodiernamente, os "efeitos" da falha estatal em garantir os direitos fundamentais instituídos constitucionalmente para todos têm sido tratados como "causa" dos problemas sociais existentes. Portanto, o correto seria considerar a violência urbana como um efeito da falta de acesso a serviços essenciais, das disparidades sociais, da precarização das relações de trabalho e da manutenção dos ciclos intergeracionais da pobreza, dado que, invariavelmente, tais problemas sociais figuram como consubstanciadores do aumento da criminalidade, não o contrário.

Isto posto, constata-se que, a violência juvenil deve ser solucionada a partir da atuação do Estado e da sociedade diante das diferentes vicissitudes sociais que a originam. Todavia, o sentimento punitivista preocupa-se tão somente com as questões emergenciais advindas da expropriação dos direitos fundamentais, propondo soluções imediatistas, quais sejam, o "aumento desproporcional de penas, maior encarceramento, supressão de direitos e garantias processuais, endurecimento da execução penal, entre outras medidas igualmente severas" (PASTANA, 2009, p. 124). Consequentemente, a defesa da redução da maioridade penal mascara o descaso do Estado com as causas que geram a prática de crimes por crianças e adolescentes, além de proporem o afastamento do direito penal da consolidação democrática contemporânea.

É forçoso, diante do contexto atual, discutir a questão da redução da maioridade penal sem a influência dos mitos que se perpetuam dentro da sociedade, os quais, fazem com que a população, de forma equivocada, clame por uma maior intervenção estatal no campo penal. Nesse segmento, os mitos ${ }^{5}$ são utilizados para explicar um determinado fenômeno social com base nas primeiras impressões que temos a respeito dele, no presente caso, eles criam expressões que traduzem-se em respostas inverídicas para justificar a redução da maioridade penal, baseadas em aspectos culturais, sociais e institucionais, próprios da sociedade brasileira.

Assim sendo, no que tange ao tema maioridade penal, é imprescindível a análise e refutação dos mitos que circundam a problemática ora discutida, os quais podem ser assim descritos: 1) os jovens são recorrentemente autores de condutas violentas; 2) a redução da maioridade penal diminuiria a criminalidade; 3) as medidas socioeducativas previstas no ECA sustentam a impunidade dos jovens infratores; 4) o adolescente já é capaz de determinar-se para não cometer infrações penais.

${ }^{5}$ CUSTÓDIO, André Viana; VERONESE, Josiane Rose Petry. Crianças Esquecidas: o trabalho infantil doméstico no Brasil. Curitiba: Multidéia, 2009. 232 p. Adesmistificação dos mitos sociais com o intuito argumentar contra a redução da maioridade penal foi inspirada na abordagem de Custódio e Veronese a respeito dos mitos representativos presentes na questão do trabalho doméstico infantil. Segundo esses autores, "Se além das dimensões econômicas, o trabalho infantil doméstico encontra reforço ideológico em questões de ordem cultural, quais seriam os elementos representativos dessa condição? Os caminhos para possíveis respostas neste campo podem ser encontrados nos mitos representativos das amarras culturais e institucionais, produzidos ao longo da história brasileira" (2009, p. 82). A mesma análise demonstra-se pertinente para a questão da redução da maioridade penal no Brasil, a qual tem sido discutida a partir de achismos, isto é, mitos sociais e representativos, próprios de fatores históricos, políticos e culturais presentes na sociedade brasileira. 
Isto posto, a fim de contrapor o senso comum, torna-se necessária e indispensável a análise da problemática ora proposta sob a luz de dados científicos, o que tem o condão de expor a real situação concreta da criminalidade infantojuvenil no Brasil, desmistificando ideias errôneas que propagam o reducionismo e maior encarceramento como solução para uma problemática social cujas raízes envolvem aspectos sociais muito mais profundos.

O primeiro mito utilizado como fundamento para a redução da maioridade penal afirma que "os jovens são recorrentemente autores de condutas violentas", o que, portanto, justificaria um tratamento mais rígido por parte da justiça penal.

Em conformidade com Sousa, Oliveira e Campos (2014, p. 227), os defensores da redução da maioridade penal alegam que tal posicionamento "se justifica na medida em que cada vez mais adolescentes têm incidido no cometimento de atos infracionais de grave potencial, notadamente homicídios". Entretanto, os autores realizaram uma análise a respeito da incidência infracional infantojuvenil na comarca de Belo Horizonte e, através dos dados coletados, concluíram que "infrações com grave potencial ofensivo constituem exceções nas práticas perpetradas por adolescentes em trajetória infracional" (SOUSA; OLIVEIRA; CAMPOS, 2014, p. 228).

Nesse mesmo sentido, de acordo com o Levantamento Anual SINASE 2016 ${ }^{6}$, organizado pelo Ministério dos Direitos Humanos - MDH, em 2018, no ano de 2016, os atos infracionais praticados em maiores proporções pelos adolescentes era o roubo (47\%), seguido pelo tráfico (22\%). Em se tratando das infrações análogas a crimes contra a pessoa (homicídio consumado ou tentado), contra a dignidade sexual (estupro) e contra o patrimônio com resultado morte (latrocínio), os dados indicaram que as proporções eram de $13 \%, 1 \%$ e 2\% respectivamente. Ademais, o Levantamento Anual esclarece que os dados de 2016, se comparados aos dados verificados em 2010, apontam para a ocorrência de uma diminuição da prática dessas infrações de maior gravidade (BRASIL, 2018, p. 17). Destarte, ao contrário do que defende o senso comum, os dados afirmam com clareza que, de todos os atos infracionais, 15\% correspondem a infrações com grave potencial ofensivo, o que afasta da realidade o mito de que os jovens são, em grande maioria, autores de crimes violentos.

Em consonância com o exposto, Cerqueira e Coelho (2015, p. 19), a partir da análise de dados, concluem que:

Com base em dados do Conselho Nacional do Ministério Público, verificamos que a parcela de Representação por Ato Infracional capitulados como crimes contra a vida, feitas pelo Ministério Público em 2013 representava 8\% do total desse tipo de denúncia. Ou seja, ao contrário do senso comum (segundo o qual a onda de criminalidade violenta no país se deve aos menores de idade), as denúncias de crimes contra a vida praticados por maiores de idade representavam cerca de $92 \%$ do total de casos.

\footnotetext{
${ }^{6}$ Os dados do Levantamento Anual do SINASE 2016 são referentes à situação do atendimento socioeducativo até a data de 30 de novembro de 2016, de modo que a sistematização dos dados enviados pelos órgãos gestores do Sistema Nacional de Atendimento Socioeducativo - SINASE, em âmbito estadual e distrital à Coordenação-Geral do SINASE da Secretaria Nacional dos Direitos da Criança e do Adolescente - SNDCA, órgão do MDH, foi apresentada no ano de 2018.
} 
Outrossim, nos casos de mortes violentas, a população jovem tem sido a cada ano mais vitimada ${ }^{7}$ o que diz muito a respeito da falha estatal em prover a proteção da juventude brasileira. Infelizmente, essa realidade fica obscurecida tendo em vista que os meios de comunicação em massa preferem proliferar exaustivamente, de maneira sensacionalista ${ }^{8}$, o envolvimento de um jovem infrator em crimes contra a vida, perpetuando no imaginário da sociedade a imagem estigmatizada do jovem em conflito com a lei.

O segundo mito social a ser esclarecido alega que a redução da maioridade penal atuaria positivamente na diminuição da criminalidade no Brasil. Essa afirmação é proveniente dos ideais punitivistas presentes na sociedade contemporânea, os quais, como dito, fornecem respostas à criminalidade que consistem, basicamente, "em penas severas, traduzidas na ausência do respeito às garantias constitucionais e no recurso amplo ao encarceramento" (PASTANA, 2009, p. 134). Porém, a solução pautada na pura e simples repressão não traz benefícios a curto, médio ou longo prazo se considerarmos a falha do sistema carcerário do Brasil que, no lugar de promover a ressocialização do apenado, atua como uma verdadeira escola do crime. Nas palavras de Guerra (2016, p. 249):

Acredita-se numa relação proporcional, mesmo sem dados que a confirmem, na qual mais punição corresponde a menos criminalidade. Entretanto, enquanto o sistema prisional mostra a falência dessa relação por meio da superlotação, o sistema socioeducativo aposta na mudança de vida do jovem.

Nessa conjuntura, a realidade demonstra que não há uma relação positiva entre o endurecimento penal e a diminuição do crime, inclusive no que tange a redução da maioridade penal. Com base nas análises qualitativas realizadas por Lins, Figueiredo Filho e Silva (2016, p. 131-133), constata-se que nos países em que o patamar legal da maioridade penal é mais elevado, menor é o nível de violência. Sendo assim, os resultados obtidos pelos autores demonstraram que "a redução da maioridade penal não está associada a diminuições nos indicadores de violência. Pelo contrário, em média, países com limites mais reduzidos de maioridade penal e responsabilidade criminal são mais violentos" (LINS; FIGUEIREDO FILHO; SILVA, 2016, p. 133).

Tanto a pesquisa no âmbito nacional, quanto no âmbito internacional ${ }^{9}$, colaboram para validar o entendimento de que a redução da maioridade penal não é medida plausível para coibir a violência juvenil. Nesse cenário, defender o reducionismo como solução para o fenômeno social da criminalidade infantojuvenil é buscar uma solução imediata e ineficaz, a qual não cumpre o papel de diminuir a

\footnotetext{
${ }^{7}$ Conforme dados do Atlas da Violência de 2018 (2018, p. 32-39), produzido pelo Instituto de Pesquisa Econômica Aplicada IPEA, em parceria com o Fórum Brasileiro de Segurança Pública - FBSP. Para ter acesso direto ao documento, acesse: $<\mathrm{http}$ ://www.forumseguranca.org.br/publicacoes/atlas-da-violencia2018/>.

${ }^{8}$ Atualmente, a propagação do reducionismo como solução ao fenômeno da criminalidade precoce tem sido corroborada pelo sensacionalismo midiático, o qual, fomenta o estigma de que as infrações cometidas por adolescentes têm gravidade igual à dos crimes cometidos por adultos, o que justificaria um tratamento penal mais rigoroso. Além disso, quando um jovem comete um crime contra a vida, a mídia trata tal fenômeno como regra, quando, na verdade, trata-se de exceção.

${ }^{9}$ Os estudos internacionais de Webster and Doob, Lee e McCrary $(2003,2005,2009)$, os quais pautaram essa colocação são citados por Cerqueira e Coelho $(2015$, p. 7) e, invariavelmente, concluem que longas penas são ineficazes como medida de controle da criminalidade.
} 
criminalidade, mas favorece que as causas intrínsecas a essa problemática sejam negligenciadas por parte do Poder Público e da sociedade como um todo, em outras palavras, "têm-se questões anteriores ao rebaixamento da imputabilidade penal que a sociedade brasileira deveria se preocupar. É o velho senso nacional de que tudo se resolverá com uma simples alteração normativa” (SOUSA; OLIVEIRA; CAMPOS, 2014,p. 229).

Isto posto, o próximo mito que se mantém presente nos debates acerca da redução da maioridade penal no Brasil argumenta que as medidas socioeducativas previstas no ECA favorecem a impunidade para os adolescentes autores de atos infracionais. Esse mito é consequência da falta de conhecimento da população sobre a metodologia das medidas socioeducativas, além disso, o grande problema está na falta de aplicação efetiva do que dispõe o referido estatuto, visto que há obstáculos presentes no caso concreto que impedem aplicação eficiente dos parâmetros legais, tais como, a inadequação das instituições socioeducativas e defasagem dos serviços oferecidos pelo SINASE ${ }^{10}$.

O ECA prevê em seu art. 104 que, apesar de os menores de 18 anos serem inimputáveis, eles devem ser submetidos a um sistema especial de controle judicial quando se encontrarem em situação irregular. Nesse sentido, aos adolescentes com idade entre 12 e 18 anos são aplicadas as chamadas medidas socioeducativas, as quais têm a prerrogativa de promover a responsabilização dos adolescentes em conflito com a lei, por meio de um processo legal adequado a peculiar condição de desenvolvimento, própria da fase da adolescência.

Vale destacar que o ECA prevê em seu art. 112 sete tipos de medidas socioeducativas diferentes, as quais devem ser direcionadas levando-se em consideração a gravidade do ato infracional cometido. Dessa forma, a partir da constatação da prática de infração, a autoridade competente poderá aplicar medidas em meio aberto, quais sejam a advertência; obrigação de reparar o dano; prestação de serviço à comunidade; e liberdade assistida. Em contrapartida, também poderão ser impostas as medidas em meio fechado, ou seja, a inserção em regime de semiliberdade; internação em estabelecimento educacional e, quando se fizer necessário diante do caso concreto, a internação provisória. De resto, o mencionado dispositivo também aduz que ao adolescente em conflito com a lei também serão infligidas qualquer uma das medidas previstas no art. 101, I a VI.

É importante assinalar que o ECA determina que "a medida aplicada ao adolescente levará em conta a sua capacidade de cumpri-la, as circunstâncias e a gravidade da infração" (BRASIL, 1990). Sendo assim, tais medidas são determinadas em correspondência com a gravidade do ato infracional cometido, sendo que as mais severas contemplam a restrição da liberdade, o que afasta da realidade o mito de que as medidas socioeducativas favorecem a impunidade dos jovens infratores. Em consonância com o exposto, aduzem Silva e Oliveira (2015, p. 23) que:

\footnotetext{
${ }^{10}$ O SINASE é um sistema integrado com o intuito de articular os três níveis governamentais para a promoção do desenvolvimento de programas de atendimento relacionados a aplicação das medidas socioeducativas no país. Esse sistema foi instituído pela Resolução n 119, de 11 de dezembro de 2006, do Conselho Nacional dos Direitos da Criança e do Adolescente-CONANDA.
} 
As medidas socioeducativas são, portanto, sanções impostas aos adolescentes em conflito com a lei que buscam, de um lado, punir a fim de que esses jovens possam refletir e reparar os danos causados e, de outro, reeducar para lograr nova reinserção social, familiar e comunitária. A impunidade do adolescente é, portanto, um mito compartilhado por muitos que contribui para reiterar o desconhecimento da população e abrir caminho para a proposta de redução da maioridade penal. As regras, as leis e as sanções existem.

Como dito, o problema não está na legislação do ECA, mas sim na plena aplicação concreta das medidas socioeducativas previstas pelo referido diploma legal. Nesse cenário, em conformidade com os dados do Levantamento Anual SINASE 2016, do total de 26.450 atendidos pelo sistema socioeducativo, $98 \%$ dos jovens estavam sendo submetidos a uma medida restritiva de liberdade, enquanto que as outras medidas em meio aberto - estavam sendo aplicadas a apenas 521 dos adolescentes em conflito com a lei. Em relação ao número de infrações, os dados demonstram que foram praticados 27.799 atos infracionais para 26.450 adolescentes em atendimento socioeducativo em todo o país. Essa diferença de número ocorre em virtude de que pode ser atribuída a autoria de mais de um ato infracional a um mesmo indivíduo. Além disso, a autoria das infrações pelo sexo masculino, em âmbito nacional, representa a quase totalidade, calculada em pouco mais de $96 \%$.

Vale pontuar que, os estados brasileiros em que havia um maior número de jovens sendo atendidos pelo SINASE era São Paulo e Rio de Janeiro, com um total de 9572 e 2293 adolescentes, respectivamente. Além disso, os dados também atestaram que no Brasil, em 2016, havia um total de 477 unidades de atendimento socioeducativo, as quais, estavam concentradas na região Sudeste, com 218 unidades, ou seja, $45,7 \%$ do total dos estabelecimentos presentes no país.

Ante o exposto, evidencia-se que a maioria das medidas socioeducativas aplicadas correspondem àquelas ditas mais graves, de caráter fechado. Aliás, na região em que há um maior número de adolescentes sendo atendidos pelo SINASE, há também mais unidades de atendimento socioeducativo. Logo, não há que se falar em impunidade, tendo em vista que as medidas socioeducativas vêm sendo aplicadas em grandes proporções, inclusive, “muitas vezes a justiça juvenil não é aplicada conforme as disposições estabelecidas no ECA e no SINASE e costumam ser mais severas do que o ato infracional requer" (SILVA; OLIVEIRA, 2015, p. 25), o que pode ser confirmado pelo fato de que a maioria das medidas aplicadas são as de restrição e privação de liberdade.

Finalmente, o último mito propagado como fundamento ao reducionismo afirma que o adolescente já é capaz de determinar-se para não cometer infrações penais em virtude de ter o pleno discernimento para distinguir o justo do injusto. Atualmente, esse mito tem grande aceitação social, entretanto, no campo científico, o mero encarceramento é visto de forma negativa ao processo de desenvolvimento infantojuvenil, porquanto, defende-se que o reajustamento do adolescente infrator deve ser pautado, sobretudo, na educação, a fim de alcançar resultados positivos e permanentes na sua recuperação e reinserção social. Nas palavras de Cunha, Ropelato e Alves (2006, p. 652): 
Embora a sociedade deseje a punição do infrator, ela também espera que, ao sair da prisão, ele deixe de cometer atos infracionais. Se o sistema penal atende à primeira necessidade social, não atende à segunda. O investimento e a reestruturação das instituições criadas para executar as medidas socioeducativas do ECA poderão ser o caminho para o atendimento às duas demandas sociais. $\mathrm{O}$ adolescente é punido ao ser internado e retirado do meio social e, paralelamente, é submetido a programas que privilegiem sua reinserção social por meio de atividades pedagógicas e de preparação para o trabalho.

É importante reiterar que, atualmente, o ordenamento jurídico brasileiro estabelece a inimputabilidade ao menor de 18 anos autor de atos infracionais com base no reconhecimento de que, nesse período da vida, o indivíduo encontra-se em uma peculiar fase de desenvolvimento, a qual justifica o direcionamento de um tratamento diferenciado por parte da justiça penal aos adolescentes em conflito com a lei. Nesse sentido, as medidas socioeducativas previstas no ECA têm uma finalidade distinta da pena prevista no Código Penal brasileiro, em razão de que elas pretendem não apenas a responsabilização do infrator, mas a promoção de sua reeducação, recuperação e reinserção social, considerando o estágio de amadurecimento físico, psicológico e cognitivo característico da adolescência. Nesse seguimento, hodiernamente, as leis destinadas à criança e ao adolescente no Brasil dão ênfase ao caráter ressocializador das medidas socioeducativas, o que também se justifica pela maior possibilidade de o adolescente trilhar um caminho diferente se lhe forem ofertadas as oportunidades e garantidos os direitos de que necessita.

Outra questão que merece ser suscitada em relação ao mito de que o jovem já pode determinar-se diante da escolha entre o lícito e o ilícito é de que os adolescentes infratores estão, em sua maioria, submetidos a uma realidade cheia de vulnerabilidades e pela expropriação de seus direitos, o que revela a dívida social do Estado, da sociedade e da família em promover a proteção integral infantojuvenil indistintamente. A realidade do Estado brasileiro demonstra que "muitos adolescentes convivem cotidianamente não apenas com o descumprimento das determinações específicas para o atendimento socioeducativo, mas também com a violação de seus direitos como adolescentes, previstos no ECA”(SILVA; OLIVEIRA, 2015, p. 19).

Enfim, diante da desmistificação dos mitos que permanecem no imaginário social sobre a questão da criminalidade infantojuvenil, evidencia-se uma crítica em relação ao sentimento de vingança social, próprio de uma sociedade abastada com a falta de segurança, o qual desvia o foco da responsabilidade estatal em promover políticas públicas e criar mecanismos capazes de inibir os fatores sociais que são preponderantes para a ocorrência da do fenômeno da violência infantojuvenil, dentre os quais, pode-se citar a desigualdade social, a violência urbana, a falta de educação adequada e falha na garantia dos direitos fundamentais para as crianças e adolescentes do Brasil. Por conseguinte, resta à sociedade indagar sobre o que teriam sido os jovens infratores de hoje, se tivessem tido acesso à proteção integral de seus direitos, garantidos na Constituição Federal e no ECA" (SILVA; OLIVEIRA, 2015, p. 6).

Portanto, é correto afirmar que a criminalidade infantojuvenil está interligada a diversas causas sociais, que vão desde a convivência social do indivíduo até a supressão de seus direitos fundamentais. Assim sendo, levando-se em consideração a falha do sistema carcerário do Brasil, que carrega consigo um 
verdadeiro atestado de ineficiência, por transfigurar-se em um aparato que incorpora e opera mecanismos de segregação, indo de encontro com sua finalidade inicial de proteção social e ressocialização, a redução da maioridade penal além de incompatível com a realidade social e jurídica do Brasil, é solução inócua para a questão da criminalidade juvenil.

\section{METODOLOGIA}

O presente artigo foi elaborado no sentido de expor as principais questões sociojurídicas que atestam a inaplicabilidade das propostas de redução da maioridade penal no Brasil. Para tanto, a pesquisa de caráter básico, foi produzida por meio do método de abordagem dedutivo, em conjunto com análise qualitativa dos dados encontrados. Ademais, foram utilizadas as técnicas de pesquisa bibliográfica, por meio da leitura de livros, teses e artigos, complementada pela análise documental, realizada através da consulta de parte fundamental da legislação voltada para o assunto em análise.

\section{CONSIDERAÇÕES FINAIS}

De acordo com o estudo ora proposto, resta evidente que a redução da maioridade penal não figura como uma solução permanente para o problema da criminalidade precoce na vida dos jovens brasileiros, por outro lado, pode acabar piorando esse cenário, visto que que os argumentos favoráveis à manutenção do sistema carcerário atual estão saturados e vencidos pela árdua realidade da ineficiência na promoção de ressocialização e organização de um aparato punitivo que tenha outra finalidade além de servir de subterfúgio para o interesse de classes privilegiadas.

Pelo que foi exposto, é notório que, com base na legislação vigente, concebemos o crime de forma diferente do ato infracional, o qual corresponde a uma espécie de punição adaptada para a criança e ao adolescente. Os pressupostos que regem os conceitos de ato infracional e das medidas socioeducativas estão firmados em sólidos documentos internacionais. Dessa forma, torna-se claro que as medidas adotadas no ECA são de proteção a uma etapa da vida que é muito controversa, tanto para as crianças e adolescentes, quanto para quem observa essa fase de maneira remota.

Ademais, em se tratando das propostas reducionistas, amplamente difundidas pelo sentimento de vingança social, além de não serem adequadas para resolver a questão em toda a sua extensão, são incabíveis do ponto de vista jurídico, ao passo em que o direito individual de inimputabilidade penal até os 18 anos de idade completos, apresenta-se como cláusula pétrea, quando se faz a análise sistemática das normas constitucionais.

Outro ponto relevante que sustenta esse entendimento é a própria falha do Estado em aplicar a Teoria da Proteção Integral, posto que, a realidade social dos jovens brasileiros demonstra que muitos não têm seus 
direitos garantidos, o que contribui para o aumento da violência juvenil. Ficou claro, ainda, a necessidade de desqualificação da narrativa punitivista, cultivada pela sociedade brasileira, a qual evidencia-se diante da desconstrução do jovem como centro das causas da criminalidade, fato que vai de encontro aos discursos, frustrados e reiterados, que tornam a prerrogativa reducionista mais ampla.

Diante do cenário em exame, é coerente que deve ser proporcionado ao jovem infrator, além da ideia de socialização, os meios necessários para se alcançar de maneira concreta a própria socialização, a fim de superar o juízo de naturalização da criminalidade juvenil, em que se pautam os julgamentos que circundam as discussões sobre maioridade penal no país, os quais acabam por preterir as reais causas do problema social em questão.

Portanto, no panorama hodierno, em que todas as medidas orbitam em torno da punição, pensar em alternativas a esse sistema transfigura-se em um trabalho significativo. Dessa forma, constata-se que os processos de criminalização não promovem a atenuação dos casos de delitos, mas configuram-se como um fator originário para o acréscimo da desigualdade e recaem, primordialmente, em circunstâncias que auxiliam a imobilidade social dos jovens que se encontram na periferia do sistema, encadeando, assim, um labirinto punitivo que eleva a criminalidade quase ao patamar existencial.

\section{REFERÊNCIAS BIBLIOGRÁFICAS:}

ANDRADE, Luis Fernando de. A impossibilidade da redução da maioridade penal no Brasil. Conteúdo Jurídico, Brasília, $\quad 25$ jan. $\quad 2013$. Dis poníve 1 e m : $<$ http://www.conteudojuridico.com.br/consulta/Artigos/33641/a-impossibilidade-da-reducao-damaioridade-penal-no-brasil>. Acesso em: 28 out. 2020.

ASSEMBLEIA GERAL DAS NAÇÕES UNIDAS. Regras das Nações Unidas para a Proteção dos Menores Privados de Liberdade. Nova York, 14 dez. 1990.

ASSEMBLEIA GERAL DAS NAÇÕES UNIDAS. Resolução 45/112. Adotados e proclamados pela Assembleia Geral das Nações Unidas por meio da Resolução 45/112, de 14 de dezembro de 1990, apresenta diretrizes para a prevenção do envolvimento de jovens com a criminalidade. Princípios Orientadores das Nações Unidas para a Prevenção da Delinquência Juvenil: Diretrizes de Riad. Nova York, dez. 1990.

BARATTA, Alessandro. Criminologia Crítica e Crítica do Direito Penal: Introdução à Sociologia do Direito Penal. Rio de Janeiro: Editora Revan: Instituto Carioca de Criminologia. 2011.

BRASIL. Constituição da República Federativa do Brasil. Brasília, DF: Congresso Nacional, 5 out. 1988. BRASIL. Decreto-lei nº 2.848, de 7 de dezembro de 1940. Código Penal. Brasília, DF: Congresso Nacional, 7 dez. 1940.

BRASIL. Decreto $n^{\circ}$ 99.710, de 21 de novembro de 1990. Promulga a Convenção sobre os Direitos da 
Criança. Convenção Sobre os Direitos da Criança. Brasília, DF: Congresso Nacional, 21 nov. 1990.

BRASIL. Lei no 8069, de 13 de julho de 1990. Dispõe sobre o Estatuto da Criança e do Adolescente e dá outras providências. Estatuto da Criança e do Adolescente. Brasília, DF: Congresso Nacional, 13 jul. 1990.

BRASIL. Superior Tribunal Federal. Ação Direta de Inconstitucionalidade n. 939-7. Relator: Ministro Sydney Sanchez. Brasília, DF, 15 de setembro de 1993. Ação Direta de Inconstitucionalidade N. 939-7. Brasília, 15 dez. 1993.p. 160-311A.

CAMPOS, Luiza Hermeto Couitinho; SOUSA, Diego Mendes de; OLIVEIRA, Letícia Cancela de. Redução da Maioridade Penal: discussão acerca dessa propagada solução para a redução da criminalidade juvenil. Revista Eletrônica do Curso de Direito da UFSM, [s.1.], v. 9, n. 1, p.210-232, 15 ago. 2014. Universidade Federal de Santa Maria.

CERQUEIRA, Daniel; COELHO, Danilo Santa Cruz. Redução da Idade de Imputabilidade Penal, Educação e Criminalidade Violenta no Brasil. Rio de Janeiro: Nota Técnica Ipea, set. 2015. 25 p.

CUNHA, Paula Inez; ROPELATO, Raphaella; ALVES, Marina Pires. A redução da maioridade penal: questões teóricas e empíricas. Psicologia: Ciência e Profissão, Brasília, v. 26, n. 4, p.646-659, dez. 2006.

Departamento Penitenciário Nacional - DEPEN. Levantamento Nacional de Informações Penitenciárias -Infopen: Atualização-junho de 2017. Brasília, 2019.74 p.

FOUCAULT, Michel. Vigiar e punir: nascimento da prisão. $29^{\mathrm{a}}$ ed. Tradução de Raquel Ramalhete. Petrópolis, RJ: Vozes, 2004.

FURTADO, Elisangela Semedo; SOUSA, Óscar Conceição de. A Criminalidade Infanto - Juvenil: Intervenção Adotada pelo Centro Educativo na Recuperação dos Jovens Delinquentes que cumprem a Medida Tutelar Educativa. 2014. 130 f. Dissertação (Mestrado) - Curso de Serviço Social, Instituto de Serviço Social, Universidade Lusófona de Humanidades e Tecnologias. Faculdade de Ciências Sociais, Educação e Administração, Lisboa, 2014.

GUERRA, Andréa Máris Campos. Contra o reducionismo na redução da maioridade penal. Psicologia em Revista, Belo Horizonte, v. 22, n. 1, p. 245-253, abr. 2016.

JESUS, Damásio de. Direito penal, volume 1: Parte geral. 34º ed. São Paulo: Saraiva, 2013.

LIBERATI, Wilson Donizete. Adolescente e Ato Infracional: Medida Socioeducativa é Pena? $2^{\circ}$ ed. São Paulo, Malheiros Editores, 2012.

LINS, Rodrigo; FIGUEIREDO FILHO, Dalson; SILVA, Lucas. A redução da maioridade penal diminui a violência? Evidências de um estudo comparado. Opinião Pública, Campinas, v. 22, n. 1, p.118-139, abr. 
2016.

MACHADO, Érica Babini; SANTOS, Milena de Oliveira. Punitivismo, Criminologia e a Importação de Teorias: Um Estudo a Partir do Procedimento de Apuração do Ato Infracional. Revista da AJURIS. Porto Alegre, v. 45, n. 144, jun. 2018.

Ministério dos Direitos Humanos - MDH. Levantamento Anual SINASE 2016. Brasília: Ministério dos Direitos Humanos, 2018.

PASTANA, Débora. Justiça Penal Autoritária E Consolidação Do Estado Punitivo No Brasil. Revista de Sociologia e Política, Curitiba, v. 17, n. 32, p.121-138, fev. 2009.

PASTANA, Débora Regina. Os Contornos do Estado Punitivo no Brasil. Revista da Faculdade de Direito da UFPR. Paraná, v.46, 2007.

SILVA, Enid Rocha Andrade da; OLIVEIRA, Raissa Menezes de. O Adolescente em Conflito com a Lei e o Debate sobre a Redução da Maioridade Penal: esclarecimentos necessários. Brasília, n. 20: Nota Técnica Ipea, jun. $2015.43 \mathrm{p}$. 